\title{
MANCHA AREOLADA CAUSADA POR Thanatephorus cucumeris EM MOGNO AFRICANO
}

\section{LUADIR GASPAROTTO ${ }^{1}$, ROGÉRIO E. HANADA², FERNANDO C. ALBUQUERQUE ${ }^{3} \&$ MARIA DE LOURDES R. DUARTE ${ }^{3}$}

\begin{abstract}
'Embrapa Amazônia Ocidental, Cx. Postal 319, CEP 69011-970, Manaus-AM, e-mail: gasparot@cpaa.embrapa.br; ${ }^{2}$ Instituo Nacional de Pesquisas da Amazônia, Cx. Postal 478, CEP 69011-970, Manaus, AM; ${ }^{3}$ Embrapa Amazônia Oriental, Cx. Postal 48, CEP 66017-970, Belém-PA
\end{abstract}

(Aceito para publicação em 18/04/2001)

Autor para correspondência: Luadir Gasparotto

GASPAROTTO, L., HANADA, R.E., ALBUQUERQUE, F.C. \& DUARTE, M.L.R. Mancha areolada causada por Thanatephorus cucumeris em mogno africano. Fitopatologia Brasileira 26:660-661. 2001.

\section{RESUMO}

O mogno africano (Khaya ivorensis) foi introduzido no Brasil para substituir o mogno brasileiro (Swietenia macrophylla) devido a sua alta resistência ao microlepidóptero Hypsiphyla grandella, a principal praga do mogno brasileiro. Em 1999, observou-se alta incidência da mancha areolada, causada por Thanatephorus cucumeris em viveiros e áreas de plantios definitivos de mogno africano nos Estados do
Amazonas e Pará, causando lesões em folhas maduras e 100\% de queda das folhas jovens. Nas folhas jovens surgem pequenas lesões marrons circundadas por uma margem púrpura e em folhas maduras as manchas são marrom-claras, exibindo anéis concêntricos.

Palavras-chave: Khaya ivorensis, Swietenia macrophylla, doença fúngica.

\section{ABSTRACT \\ Target leaf spot caused by Thanatephorus cucumeris on African mahogany}

African mahogany (Khaya ivorensis) introduced in Brazil in recent years has been preferred to reforest devastated areas to replace Brazilian mahogany (Swietenia macrophylla) due to its high-quality timber and its high resistance to Hypsiphyla grandella, the major pest of Brazilian mahogany. Since 1999 a high incidence of target leaf spot caused by Thanatephorus cucumeris has been observed in nursery and in field, in the States of Amazonas and Pará (Brazil), causing numerous zonate lesions on mature leaves and $100 \%$ leaf fall in seedlings. Young leaves of diseased plants initially show little brown spots surrounded by a purple margin, while in mature plants the lesions are light brown exhibiting concentric rings resembling a target.
Devido à alta suscetibilidade do mogno brasileiro (Swietenia macrophylla King) ao microlepidóptero Hypsiphyla grandella Zeller, essa essência florestal vem sendo substituída pelo mogno africano (Khaya ivorensis A. Chev.), introduzido recentemente na Região Amazônica para plantios em escala comercial.

Em mognos africanos, com cerca de dois anos de idade, implantados na área experimental da CEPLAC, situada na margem esquerda da Rod. 174, km 48, e da Embrapa Amazônia Ocidental, situada na margem esquerda da Rod. AM-010, km 29, município de Manaus-AM, constatou-se, em dezembro de 1999, uma doença causando $100 \%$ de queda das folhas do último lançamento foliar. No mesmo ano, foi observada a ocorrência de doença semelhante em plantios de mogno africano no município de Igarapé Açu, estado do Pará.

Em Manaus, as infecções ocorrem apenas em folhas jovens quando apresentam coloração avermelhada. Inicialmente, os sintomas se apresentam como manchas arredon- dadas com cerca de 2 a $8 \mathrm{~mm}$ de diâmetro, centro esbranquiçado, bordos escuros e circundados por um halo cor vinho, com 1 a $3 \mathrm{~mm}$ de largura (Figura $1 \mathrm{~A}$ ). Quando a folha atinge a maturação, formam-se manchas grandes, marrom-claras ou marrom-escuras, descontínuas, necróticas e em forma de auréolas (Figura $1 \mathrm{~B}$ ). Folhas com lesões de grandes proporções ou apenas situadas nos seus terços basais e próximo à nervura principal tendem a cair. Em condições de elevada umidade, e especialmente nos folíolos caídos no chão, observase, sobre as manchas na superfície abaxial, um manto micelial esbranquiçado do patógeno, facilmente visível quando a folha afetada é observada contra a luz.

Em Igarapé Açu observou-se que, nas folhas maduras, as manchas se iniciam a partir de uma lesão diminuta $(0,5$ $\mathrm{mm}$ ), com centro claro rodeado por uma margem pardoescura, surgindo anéis concêntricos de coloração marromclara. Com o progresso da doença, a área central da lesão adquire uma tonalidade prateada, ficando a área zonada 


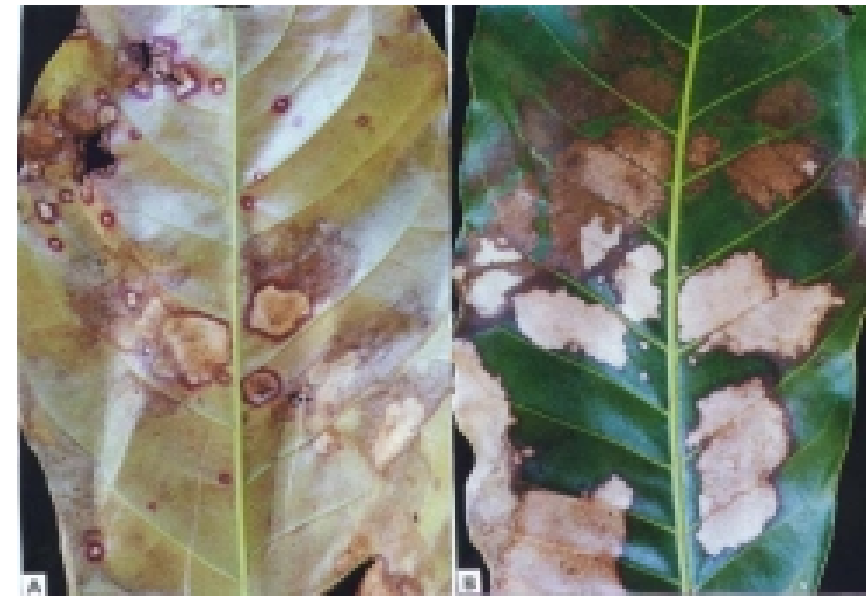

FIG. 1 - Sintomas iniciais (A) com lesões de bordos escuros e halo cor vinho e finais (B) com lesões necróticas, em forma de auréolas, causados por Thanatephorus cucumeris em folhas de mogno africano (Khaya ivorensis), nas condições de Manaus-AM.

limitada ao terço externo da lesão. A última zona de crescimento da lesão é de coloração pardo-escura, ficando o tecido sadio limitado por um tênue halo clorótico. As lesões surgem entre as nervuras secundárias, podendo permanecer isoladas ou coalescerem, mas raramente uma lesão atinge a nervura principal. Em condições de alta umidade, um micélio semelhante a uma teia, visível a olho nu, se espalha das lesões para as áreas sadias da folha. Mesmo incitando lesões numerosas, nas condições do estado do Pará, o patógeno não tem provocado a queda acentuada de folhas como acontece em citros (Citrus spp.) e seringueira (Hevea spp.). Quando ocorrem várias infeções em determinada área da folha, essa área apresenta-se necrótica com anéis concêntricos, sendo possível distinguir o ponto de penetração do patógeno. As lesões são visíveis em ambas as faces da folha, mas os anéis são mais visíveis na face inferior das folhas. Em folhas maduras, as lesões medem de 1,2 a 2,9 mm de comprimento e de 0,8 a 2,9 mm de largura. Em plantas mantidas em viveiro, o fungo causa sintomas de mancha areolada típica ou de mela.

O isolamento em meio de BDA, os testes de patogenicidade positivos em folhas jovens e maduras e as características morfológicas permitiram identificar o patógeno como sendo o fungo Thanatephorus cucumeris (Frank) Donk. (anamórfico: Rhizoctoma solani). Inoculações feitas em folhas de mudas de mogno africano com inóculo de T. cucumeris reproduziram os sintomas típicos da mancha areolada, duas semanas após a inoculação (Figura 2).

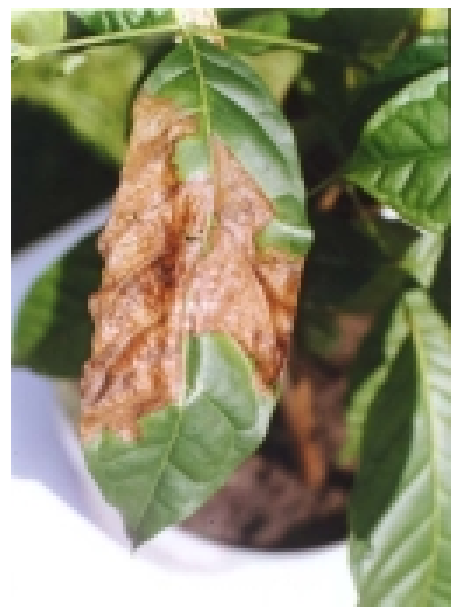

FIG. 2 - Lesões características de mancha areolada causada por Thanatephorus cucumeris em folha de mudas de mogno africano (Khaya ivorensis), com três meses de idade, duas semanas após a inoculação, nas condições de Belém-PA.

Na Amazônia, o patógeno foi constatado causando mancha areolada em seringueira (Deslandes, 1944) e em laranjeira (Lourd et al., 1984) e a doença denominada queima da téia micélica em feijoeiro (Phaseolus vulgaris L.) (Albuquerque \& Oliveira, 1973) e em maracujá (Passiflora edulis f. flavicarpa Deg.) (Poltronieri et al., 1999).

$\mathrm{O}$ ataque severo do T. cucumeris, causando sucessivos desfolhamentos de plantas com cerca de $7 \mathrm{~m}$ de altura, poderá reduzir o crescimento do mogno africano na região tropical sempre úmida, desde que as condições favoráveis à infecção ocorram durante longos períodos. Pulverizações quinzenais em viveiros, com o fungicida pencycuron ( $2 \mathrm{~g} / \mathrm{l}$ de água), têm mantido as mudas livres da doença.

\section{REFERÊNCIAS BIBLIOGRÁFICAS}

DESLANDES, J.A. Observações fitopatológicas na Amazônia. Boletim Fitossanitário 1:197-244. 1944.

LOURD, M., BRAZ ALVES, M.L. \& GASPAROTTO, L. Ocorrência da mancha areolada em citrus no município de Manaus-AM. Fitopatologia Brsileira 9:135. 1984.

POLTRONIERI, L.S., TRINDADE, D.R., ALBUQUERQUE, F.C. \& BENCHIMOL, R.L. Web blight (Thanatephorus cucumeris) on passion fruit in the state of Pará, Brazil. Fitopatologia Brasileira 24:92. 1999. (Resumo).

ALBUQUERQUE, F.C. \& OLIVEIRA, A.F.F. Ocorrência de Thanatephorus cucumeris em feijão na região Transamazônica. Belém, IPEAN, 1973. 